\title{
AS PESQUISAS COM INTELECTUAIS EM HISTÓRIA DA EDUCAÇÃO: um campo profícuo
}

\author{
Maria Cristina Gomes Machado ${ }^{1}$ \\ UEM \\ Antonio Marcos Dorigão ${ }^{2}$ \\ UNESPAR / FECEA \\ Gizeli Fermino Coelho ${ }^{3}$ \\ UNICESUMAR
}

\section{RESUMO}

Este artigo investiga a categoria intelectual, suas obras e proposições teóricas como objeto de pesquisa na área de História da Educação. A proposta problematiza os procedimentos teórico-metodológicos que devem ser adotados nessas pesquisas para alcançar resultados profícuos. Trata-se de uma análise bibliográfica que se utiliza como fonte de estudo artigos e livros dedicados à história da educação, valendo-se da obra e de ações de intelectuais e textos relacionadas à metodologia de pesquisa em história da educação. Compreende-se que os intelectuais são personalidades diretamente ligados à vida pública dotados de uma visibilidade que os aproximam dos meios políticos, culturais e midiáticos, profissionalmente produzem obras artísticas ou científicas pautadas em ideias que refletem o seu contexto histórico. Desta forma, estudar as produções e a atuação dessas personalidades no cenário intelectual requer a localização no tempo e espaço da construção de suas ideias, situando-o na rede de relações e fatos políticos, econômicos, culturais e sociais na qual forjou sua perspectiva teórica, este procedimento evita eternizar, naturalizar e universalizar as propostas de intelectuais tomadas como objeto de estudo na área de História da Educação.

Palavras- chave: Educação; Intelectuais; História da Educação; Pesquisa.

\section{THE RESEARCHES WITH INTELLECTUALS IN HISTORY OF EDUCATION: a proficuous field}

ABSTRACT

This article investigates the intellectual category, productions and theoretical propositions as an object of research in the History of Education area. The proposal discusses the theoretical and methodological procedures to be adopted in such researches in order to achieve proficuous results. This is a bibliographical analysis that uses articles and books devoted to the history of education as a source of study, making use of the work and actions of intellectuals and texts related to the research methodology in history of education. It is understood that intellectuals are personalities directly related to the public life endowed with a visibility that approach them to the political, cultural and media means, professionally produces artistic or scientific works guided by ideas that reflect its historical context. In this way, study the productions and performance of these personalities in the intellectual scenario requires the location of time and space of building their ideas, placing it in the network of relationships and political, economic, cultural and social events in which forged its theoretical perspective, this procedure avoids eternalize, naturalize and universalize the intellectuals propose taken as an object of study in the History of Education area.

Keywords: Education; Intellectuals; History of Education; Research. 


\section{INTRODUÇÃO}

A pesquisa em educação representa um terreno fértil para a construção do conhecimento científico, dada à necessidade de compreensão do papel dos sistemas educacionais na configuração social em determinado tempo e espaço. Dentre as divisões possíveis, a história e a historiografia da educação representam um ramo que possibilita a discussão de bases do contexto social no qual se inserem as propostas e ações do ensino e suas consequências sociais e políticas. Um dos caminhos para o estudo da história da educação é a análise da obra e de ações de personalidades no cenário intelectual e político em certos momentos históricos e em diferentes locais. Neste âmbito de pesquisa, Vieira (2012), em artigo publicado no Congresso Brasileiro de História da Educação, discute a produção acadêmica da História das Ideias, e aponta a ausência da contextualização social em alguns estudos que retratam a produção e a atuação dos intelectuais na história da educação.

A ausência de localização de um autor e o lugar social ocupado por ele leva a eternizar ou naturalizar suas propostas, elegendo-as abstratamente como ideias válidas e aceitas universalmente. Desses autores, ao serem tomados como objeto de estudo, esperase que respondam questionamentos atuais, para demonstrar a permanência de determinadas questões ou soluções, de modo a tratá-los como "mitos" ou "heróis" que estavam fora do seu tempo por antecipar questões que serão consenso posteriormente. Assim, "desenraizados", são chamados para reafirmar uma ideia ou como autoridade portadora de argumentos indiscutíveis, não raro descolados do contexto social em que se formataram suas obras e ações.

Diante do debate sobre a elaboração de pesquisas que tratam da história da educação mediante a análise de intelectuais, este artigo se dedica a discorrer sobre quais os procedimentos teórico-metodológicos adotados nessas pesquisas. Insiste-se na importância de que essa leitura seja realizada considerando-se o contexto social da elaboração do pensamento e propostas com base na obra dos intelectuais do século XX.

Nesta perspectiva, foram coletadas informações em artigos e livros dedicados à história da educação, valendo-se da obra e de ações de intelectuais e textos relacionadas à metodologia de pesquisa em história da educação. $\mathrm{O}$ presente estudo discute, em primeiro lugar, as definições de história e historiografia da educação, que são tomadas como base para o constructo teórico, seguidas pela análise do papel do intelectual na sociedade e o tratamento dado na elaboração de estudos sobre a produção e atuação destes atores sociais na história da educação.

\section{HISTÓRIA, HISTORIOGRAFIA E EDUCAÇÃO}

A delimitação temática deste estudo que se refere à história e à historiografia da educação é metodologicamente importante para indicar caminhos a percorrer nas pesquisas com intelectuais. Von Ranke (2010, p. 206), ao discorrer sobre o lugar da história no espaço das ciências, define a necessidade da análise em torno das "condições de vida", "no interesse sobre o particular", na especificidade analisada como parte do todo, assim "[...] a História vê o que é bom e benéfico no existente, o qual tenta captar, e direcionar seu olhar para trás". Este "olhar para trás" faz parte da atuação do historiador e, na avaliação de Von Humboldt (2010): 
[...] o historiador não pode largar o seu domínio sobre a sua exposição ao se limitar a procurar tudo na matéria objetiva; ele precisa, ao menos, deixar espaço para a ação da ideia; mais adiante, ele precisa, com o tempo, deixar sua alma receptiva para a ideia e mantê-la viva, intuí-la e reconhecê-la; precisa, acima de tudo, se precaver em não atribuir à realidade sua próprias ideias, ou ainda, em não sacrificar ao longo da pesquisa a riqueza viva das individualidades em prol do contexto totalizante. (VON HUMBOLDT, 2010, p. 82).

Para este autor, a ideia teria valor como força explicativa e poderia ser isolada e desconstruída de modo a questionar a eficácia da materialidade. Este raciocínio exige um repensar sobre o modo pelo qual operacionalizamos o rememorar da história e as teorias produzidas ao longo do tempo. Estudos realizados ao longo do século permitiriam aproximar a história dos aportes científicos necessários para o seu estudo. Diferentemente de Von Humboldt, pode-se afirmar que o contexto social do autor estudado, bem como do historiador que se propõe a realizar o estudo, é fundamental ao desenvolvimento de uma pesquisa em história da educação, evitando-se, com tal procedimento, tratar as ideias pelas ideias.

$\mathrm{Na}$ perspectiva de Lopes e Galvão (2001), a história é uma "ciência em construção", porque a conquista do seu método científico não é completa á medida que os historiadores ainda estão descobrindo os meios de análise adequados ao seu objeto. No entanto, ao olhar "para trás" o historiador da educação deve objetivar reconstruir um período histórico e, neste caso, também uma trajetória intelectual é sempre mediatizado por objetos, técnicas e métodos, instrumentos que adquiriram sentidos diversos no decorrer do desenvolvimento histórico e científico. Conforme pontuaram as autoras:

A história nos permite ver que, em outros lugares, culturas e outras épocas, a educação de modo geral, e a escola, em particular tem mudado, mas parecem manter alguns elementos intocados que surpreendentemente são os mesmos em épocas distintas, isso nos ajuda a olhar nossa realidade com paciência: afinal, as coisas demoram muito a mudar e às vezes é preciso esperar duas ou três gerações para que uma inovação educacional se estabeleça. (LOPES; GALVÃO, 2001, p. 17).

Essa inquietação referente à escrita da história tem, nas últimas décadas, provocado entre os educadores importantes reflexões epistemológicas quanto à configuração e o desenvolvimento do campo da história da educação. Contudo, alertamos para a preocupação com a utilização política daquilo que produzimos.

Durante a transição da Idade Média para a Modernidade, as alterações ocorridas na vida social levaram os homens a questionar a função da história, posto que "[...] o homem, além de um ser histórico, busca agora apropriar-se da sua historicidade. Além de fazer história, aspira a se tornar consciente dessa sua identidade". (SAVIANI, 2006, p. 141). Le Goff (1990), com base na vertente da "Nova História", trabalha com a ideia da transição e propõe ao historiador uma ação voltada à produção da história enquanto ciência. A este caberia estabelecer a distinção do simbólico no cerne de toda "realidade histórica", de modo a confrontar os aspectos históricos com as realidades que elas representam, percebendo, por meio desses apontamentos, por exemplo, “[...] a ideologia política com a práxis e os eventos políticos" lembrando que "[...] toda história deve ser uma história social”. (LE GOFF, 1990, p. 554). 
Ao apresentar uma definição mais abrangente, Cadiou et al. (2007, p. 254) apontam a história como primeiramente uma prática social, obtendo "[...] sua cientificidade não de seu objeto ou dos métodos que permitem construí-lo, mas de seu funcionamento interno", criando espaço para a constante avaliação dos resultados obtidos pelos profissionais que realizam o mesmo trabalho. A história apresenta uma característica dinâmica, multifacetada, permeada por inúmeras realidades, ficando a cargo do pesquisador a interpretação do maior número possível de fatores sociais envolvidos no seu contexto social.

Para Hobsbawn (1998, p. 243), a escrita da história, de qualquer época, é a história que considera o contexto do historiador, e exemplifica: "O grande Theodor Mommsen escrevia sobre o Império Romano como um liberal alemão da safra de 48 refletia também sobre o novo Império alemão". E o contexto do historiador é aquele no qual recebeu a sua formação, foi influenciado e o vivenciou ao longo da sua vida. Em relação a este posicionamento, encontra-se proposição similar em outro historiador do século XX:

Investigações históricas costumam sofrer da heteronomia de seus juízos de valor. Muitas vezes vigora um alto grau de imprecisão em distinguir entre aquilo que parece importante para o pesquisador, com base na escala de valores de seu próprio tempo, especialmente em função dos seus próprios ideais, e aquilo que é importante no contexto da época pesquisada - por exemplo, o que ocupava posição superior ou inferior numa escala de valores de quem estava vivo naqueles dias. A escala de valores pessoal do historiador, condicionada pelo seu tempo, geralmente leva vantagem. Ela define em grande medida o modo de colocar as questões e a seleção de fontes. (ELIAS, 2001, p. 53).

Assim, a produção na área de história é caracterizada pela sua definição enquanto ciência e as formas de análise são influenciadas pelo conhecimento e pela percepção do pesquisador, dada a sua formação e contexto social. Como outras ciências, a história se divide em áreas de conhecimento: história econômica, história da arte, história política, entre tantas outras. Assim, o estudo da história e o fazer história são atividades bastante antigas, e, por isso, seus métodos são diversos, as técnicas empregadas pelos historiadores são variadas, os temas das investigações históricas são díspares e as conclusões são controversas. (NÓVOA, 1999).

Nesta perspectiva, a formação das disciplinas científicas é um campo que compete aos historiadores estudar, e, neste estudo incluir a formação das especializações historiográficas, pois a história reparte-se em grandes números de disciplinas históricas, que são como "etiquetas" que a academia lhe incumbe, na tarefa cartesiana de dividir o real em fragmentos para mais comodamente estudá-lo, ou para acomodar uma crescente população acadêmica no poder da divisão institucional. Tem-se, desse modo, uma especialização epistemológica correndo paralelamente a uma especialização política. No caso da história da Educação, depois de um longo itinerário, acaba por constituir-se como campo autônomo dotado de um projeto próprio tangenciando outras disciplinas históricas. (CASTANHO, 2010).

Ao remeter a discussão à história da educação, a compreensão das características próprias desta área do conhecimento direciona a reflexão sobre a existência de um método diferenciado de investigação. Para Leonel (2006, p. 53), a rigor, não existiria história da educação como disciplina, visto que a educação seria integrante da história, portanto, os estudos se refeririam à história e não somente à educação. A tentativa de separar a história da educação de um contexto histórico mais amplo acaba por produzir informações 
deslocadas do contexto social que propiciou seu surgimento. Ao percorrer os argumentos desta reflexão, Lombardi (2006, p. 77) entende que "[...] o mais adequado é considerar que a História da educação está indicando o estudo do objeto de investigação - a educação - a partir de métodos e teorias próprias à pesquisa e investigação da ciência da História".

Castanho (2010) considera a legitimidade da história da educação se for feita sua articulação com a totalidade histórica. Assim, história da educação:

[...] pode estudar objetos mínimos, como certas instituições escolares individuais, mas como subordinação ao processo geral da institucionalização escolar, no âmbito do processo histórico da escolarização da educação, que por sua vez se situa no processo mais amplo da produção manufatureira, que por seu turno é um episódio da cooperação produtiva, que constitui uma realização histórica do processo de produção material da existência, que é, ao fim e ao cabo, a determinação básica de toda a história. (CASTANHO, 2010, p. 96).

Com base nesta definição de história como ciência, identifica-se o conceito de historiografia, expressão que permeia as produções do campo da história e da história da educação. A palavra historiografia é polissêmica, já que se presta a registrar em textos a história, o conhecimento instituído pela própria humanidade por intermédio do seu passado, bem como a ciência da História. Portanto, seria essencial à historiografia a explicitação dos fundamentos adotados para pesquisa e sua problematização. Somente após esta exposição o "historiador" iniciaria a análise a que se propõe.

Em outro aspecto, da mesma forma que se estabelece a relação entre história e história da educação, é estabelecida a relação entre historiografia e historiografia da educação. Neste sentido, a historiografia da educação:

[...] é um campo de estudo que tem por objeto de investigação as produções históricas que estudam a educação. Apesar de ser um campo recente, a historiografia da educação praticamente reproduziu as características da produção historiográfica, com trabalhos em que a produção no campo da história educacional é de caráter descritivo, com ênfase nos aspectos formais da produção (tema, período, fontes, etc.); há, entretanto, alguns trabalhos que fazem uma análise dessa mesma produção a partir de seus pressupostos metodológicos e teóricos. (LOMBARDI, 2006, p. 82).

Dadas às características da história como ciência e do processo de produção das investigações na área de historiografia da educação como instrumento de análise descritiva e escrita na área da educação, o encaminhamento a seguir discute o papel dos intelectuais como produtores de obras de interesse para este campo da ciência e os métodos utilizados na elaboração de pesquisas com personalidades públicas, reconhecidas pela sua atuação no campo do saber e da ação.

Para reafirmar como relevante o exercício da pesquisa em história e, a priori, o método analítico adotado comumente nos estudos dos intelectuais, destaca-se a necessidade de recuperar o significado da obra e dos autores que devem ser compreendidos em sua estreita relação com o contexto social. Esta relação entre texto (propostas e ações) e contexto legitimaria a historicidade da produção dos autores tomados como objeto de estudo, como apontado anteriormente, conforme os preceitos da pesquisa histórica. 


\section{O ESTUDO DOS INTELECTUAIS NAS PESQUISAS EM HISTÓRIA DA EDUCAÇÃO}

Para tratar do significado de intelectual, é preciso levar em consideração sua variação, seja do ponto de vista do tempo, de área de conhecimento ou de atuação. Máximo (2000, p. 15), na obra Os intelectuais e a educação das massas, assevera que "[...] um dos primeiros problemas para se estudar os intelectuais é delinear os contornos de um conceito que começa a se esboçar no século XII, mas que, a rigor, vai encontrar formas mais nítidas apenas no século XX". Assim, o processo histórico de construção do conceito de intelectual, segundo Vieira (2008, p. 70), pode ser identificado no cenário francês do final do século XIX, pela apropriação do termo intelectual, que se tornou comum o uso desse termo no plural -intelectuais -, visto que o uso da palavra no plural significa um conjunto de indivíduos com características comuns.

O uso da expressão intelectuais no século XIX converge para uma definição de longa data, "[...] uma vez que as experiências políticas de Cícero no Império Romano, Maquiavel na República de Florença ou de Voltaire na França pré-revolucionária prenunciavam esse encontro entre sábios e esfera pública". (VIEIRA, 2008, p. 70). Portanto, cada época histórica vê surgir tipos sociais que simbolizam de certa maneira a atividade intelectual. A época clássica conheceu o homem da sociedade, o nobre da corte, o filosofo das luzes, o período moderno conhece o intelectual como personagem emblemático da nossa história. Sob essa ótica, a ação dos sábios e cultos na sociedade não representa nenhuma novidade em termos históricos, contudo, no século XIX, num contexto que evidencia contradições sociais e desenvolvimento tecnológico, em especial com a presença de jornais e de revistas como porta-voz da difusão de cultura e de posições políticas, contribuiu para formar a identidade dos intelectuais como protagonistas políticos.

Desta forma, a ideia de intelectual permeia a história da humanidade e está entremeada pela imagem do conhecimento e da erudição. Na sociedade contemporânea, com o avanço do conhecimento científico, acesso à educação e a circulação de informações, é comum a identificação de indivíduos ou grupos refletindo sobre a vida social e, com base em noções comuns, indicando rumos, divulgando opiniões e agindo na sua manutenção ou modificação. Malina, Oliveira e Azevedo (2007) consideram que a produção de conhecimento realizado nas universidades em quantidade cada vez maior revela uma perspectiva de sociedade.

No século XX, a erudição e o conhecimento aliados à ação representam as características dos intelectuais. Em Sartre (1965, p.14-15), o intelectual aparece como "[...] conjunto de homens que tendo adquirido alguma notoriedade por trabalhos que dependem da inteligência, abusam dessa notoriedade para sair de seu domínio e criticar a sociedade e os poderes estabelecidos em nome de uma concepção global e dogmática do homem". Neste sentido, o intelectual ultrapassa o campo de sua competência tradicional (romancista, historiador, sociólogo, físico etc.) para falar de coisas das quais não é expet, mas em relação às quais julga-se implicado e concernido, isto é, o intelectual é aquele que se ocupa do que não lhe diz respeito, é um indivíduo intrometido, curioso por natureza, que vai além de sua ocupação, devido ao seu espírito investigador e crítico.

Para Michael Löwy (1979), o intelectual não é um homem ou mulher, mas uma dimensão da sociedade, é um ser híbrido que, profissionalmente, produz uma obra artística ou científica e que enquanto autor engajado nos assuntos da vida pública é dotado, queira ou não, de uma visibilidade que o aproxima dos homens políticos e dos homens da mídia. Os intelectuais vivem para as ideias, por uma espécie de vocação ou engajamento, suas atividades profissionais vivem antes pelas ideias ou para as ideias, embasadas pela 
aplicação prática das mesmas. Seu interesse pelas ideias enquanto tais se estruturam por uma espécie de espírito contemplativo, especulativo e crítico que se opõe de maneira mais geral ao espírito prático dos técnicos e dos profissionais.

$\mathrm{Na}$ perspectiva de Lowy (1979), o intelectual encarna o espírito crítico, contemplativo e especulativo buscando atuar na mudança social, porque insiste em falar em nome dos valores universais e de tudo o que diz respeito aos interesses humanos, esta é, portanto, a forma suprema da curiosidade intelectual, saber por saber.

O saber intelectual tem a ver essencialmente com a criação de um produto final chamado "[...] "obra" (livro, artigo de jornal, um artigo científico, partitura musical etc.) que caracteriza uma criação ou uma inovação cultural, resultante das críticas, sugestões e observações de homens que buscam intervir em seu momento histórico". (LOWY, 1979, p. 32). Assim as produções intelectuais pautadas nas ideias inovam o domínio da cultura, da estética e da ideologia, porque são apropriados e reproduzidos por leitores, ouvintes e espectadores, que o fazem ganhar amplas proporções.

Em Gramsci (1968) encontramos o debate acerca da produção de ideias pautada na identidade de cada grupo, notadamente do status econômico e social, construindo e enraizando saberes próprios de determinadas classes sociais. Beired (1998, p. 122), apoiado nos seus estudos sobre Gramsci, afirma que, para esse autor, o intelectual pode assumir uma dupla função, tanto pode agir para a transformação da sociedade quanto para a sua reprodução, avançarem no que se refere à contemplação.

Na obra de Gramsci, existe uma divisão no conceito de intelectual, definidos como tradicionais ou orgânicos. Os primeiros representam o homem culto e erudito, que busca a informação e o conhecimento, reproduzindo o padrão aristocrático de sábios, letrados e possuidores de um espírito elevado, exemplificados pelos membros do alto clero, professores, artistas e escritores. O segundo tipo está inserido na "[...] sua construção (orgânica) pelas relações sociais de força, representando, assim, implicitamente a formação do próprio mundo burguês moderno (revolução burguesa)". (CERQUEIRA, 2010, p. 2). Ao abordar a definição de intelectual orgânico de Gramsci, Vieira (2008, p. 77) o subdivide em dois tipos: "[...] o orgânico ao projeto do Estado burguês, que produz as condições ideológicas para a exploração dos trabalhadores pelo capitalismo; e o intelectual orgânico aos interesses das classes subalternas, que visa à organização de uma nova forma de domínio e de direção política".

Gramsci (1968, p. 11) afirma que a ação dos intelectuais necessita de uma classificação em diferentes graus, permitindo, em situações de oposição, ceder espaço a uma real determinação da diferença qualitativa, uma vez que, "[...] no mais alto grau, devem ser colocados os criadores das várias ciências, da filosofia, da arte, etc.; no mais baixo, os 'administradores' e divulgadores mais modestos da riqueza intelectual já existente, tradicional, acumulada".

Ao definir os intelectuais como pessoas de ação permeadas pelo uso do conhecimento no cotidiano Máximo (2000) faz a caracterização dos traços comuns que os identificam:

a) clássica divisão entre trabalho manual e trabalho intelectual (mesmo Abelardo, lá na Idade Média, já confirma isso de modo exemplar: por não saber trabalhar com as mãos - diz ele - abriu uma escola); b) a ideia gramsciana de 'funcionários das superestruturas'; c) a divisão da sociedade em classes, camadas sociais, castas, estamentos; d) a manutenção da existência material com recursos retirados do próprio trabalho não físico, isto é, 'ganha o pão' trocando ideias; e) o caráter laico 
da atividade intelectual; f) o exercício constante da crítica em geral e, particularmente, da crítica sistemática ao poder; g) a dedicação ao cultivo das ideias perenes, a vigilância com relação aos valores universalmente válidos da cultura (que não se sujeitam ao 'temporal', ao contingente), o cultivo das ideias de razão, justiça, democracia; h) a produção e difusão de conhecimentos; i) e, por fim, alguns autores recorrem até mesmo aos conceitos de 'progressistas' e de 'esquerda' para situar o que se deve entender por intelectual. É o caso, por exemplo, de Sartre e de Luiz Arangurem. (MÁXIMO, 2000, p. 21).

As características dos intelectuais indicadas por Máximo (2000) podem ser encontradas em obras que tratam da história da educação e que analisam o pensamento e a ação de personalidades públicas, reconhecidas pela sua sabedoria e influência nas questões sociais do cotidiano, como, por exemplo, Norbert Elias (1995) em Mozart-sociologia de um gênio, que faz uma análise da sociedade no século XVIII ao tomar por base o estudo das relações sociais, dos conflitos e do reconhecimento do músico Wolfgang Amadeus Mozart em Viena na Áustria.

As características propostas por Máximo, que se encontram na obra de Elias acerca de Mozart, também se apresentam nos escritos de Marrach (2009), que aponta a distinção entre os modelos aristocráticos humanistas da época do Renascimento, dominantes de todo o complexo cultural da época e os intelectuais do século XX, imersos nas sociedades de massa contemporâneas, participando do cotidiano ao realizar as mesmas interações sociais de qualquer indivíduo, mas se destacando pela possibilidade de poder assistir aos telejornais e seriados da televisão ou ler Adorno e ver um filme de Bergman, porém " [.... a mulher operária, o entregador de pizza, só podem ler fotonovelas e o horóscopo, pois eles não têm condições de compreender um poema de Pound, nem apreciar o cinema de arte e não foram preparados para entender os pensadores de Frankfurt". (MARRACH, 2009, p. 268).

No bojo do debate acerca da definição de intelectual e a construção da imagem com base nos próprios atores sociais, Vieira (2008, p. 82), por meio da análise das concepções de Manheim, Gramsci e Bourdieu, propõe um estudo dos intelectuais concomitante ao seu lugar social, às suas relações, ao grupo de pertencimento, aos acordos políticos e ao contexto no qual está inserido, posto que, embora os resultados das pesquisas realizadas nesta área "[...] sejam discrepantes, é inegável que eles partilharam da tese de que os condicionamentos estruturais do capitalismo não incidem diretamente sobre a sociedade, pois dependem de mediações culturais". O processo de mediação cultural é determinado como uma característica marcante na história das ideias do século XX, cercada e permeada pelos "[...] determinismos estruturalistas ou pelos idealismos culturalistas de diferentes extrações teóricas”. (VIEIRA, 2008, p. 82).

A respeito da questão cultural na historiografia, Donald Kelley (1987) defende que a história intelectual é a única área em que pode ser permitido o estudo sob uma grande perspectiva e a principal questão para a história das ideias é não perder suas amarras, seja numa visão do contexto social em que foi criada, seja em uma visão de como esta história será interpretada no futuro.

Ao tomarem como ponto de partida as concepções de intelectuais encontradas em Vieira (2008) e Máximo (2000), estudiosos da temática na atualidade evidenciam a existência de características comuns na definição dos intelectuais, tais como o uso do conhecimento e erudição aliados à atuação social, propondo ações de transformação ou conservação da sociedade, seja inserido nos quadros de governo ou nos movimentos sociais. Dentro desta perspectiva, fica candente a necessidade de ampliar pesquisas sobre 
as questões ou posições defendidas pelos intelectuais com vistas ao contexto em que o sujeito está inserido, identificando seu papel e significado na história intelectual, sem deixar de lado a ideia de que o posicionamento assumido está historicamente definido e, portanto, mutante no tempo e no espaço.

Para Falcon (1997, p. 142), existe uma “[...] tendência da história intelectual de romper os limites disciplinares estabelecidos, já que visa a inserir o estudo das ideias e atitudes no conjunto das práticas sociais" e, neste ponto, há convergência entre as pesquisas com intelectuais e história da educação, uma vez que ambas precisam ancorar suas fontes num contexto social amplo e multifacetado ao pretender um resultado minimamente legítimo. Inserida na área de ciências humanas, os estudos com intelectuais na história da educação, podem ser realizados de inúmeras maneiras, mas trazendo em comum característica de análise e construção/desconstrução do real e, logicamente, utilizando-se de procedimentos de registros dos dados. (FERRÉOL; NORECK, 2007, p. 66).

Lakatos e Marconi (2006) afirmam que a construção do conhecimento científico apresenta, em primeiro lugar, objetivo e finalidade, representados pela inquietação de estabelecer características comuns ou leis gerais para explicar determinados acontecimentos. Em seguida, estabelecem a função definida pelo processo de aprimoramento do acervo de saberes e conhecimentos e, por fim, o objeto, que se subdivide em: "[...] 1) material, aquilo que se pretende estudar, analisar, interpretar ou verificar, de modo geral; 2) formal, o enfoque especial, em face das diversas ciências que possuem o mesmo objeto material". (LAKATOS; MARCONI, 2006, p. 22).

Com tal pressuposto, utiliza-se como exemplo a obra Rui Barbosa: Pensamento e Ação de Machado (2002), que estuda um intelectual do século XIX com o objetivo de analisar a obra de um autor que contribuiu na defesa da escola pública com propostas de reformas, sem deslocá-lo do contexto social vivido. Para tanto, considera o conjunto de sua obra com vistas a expandir a leitura de textos do autor, mesmo aqueles em que a temática educacional não seja objeto de análise. Esse tratamento permitiu à autora alcançar conclusões diferenciadas daquelas na qual somente foram usados os textos de Rui Barbosa diretamente ligados à educação. Por meio desse tratamento, a autora defende a tese de que Rui Barbosa não considerava a educação como um motor de transformação social, já que, no seu projeto de modernização da sociedade brasileira, considerava a importância da educação atrelada a outras reformas, como a abolição da escravidão, a reforma eleitoral e a industrialização.

Pode-se afirmar que o objeto material, isto é, as fontes utilizadas, nesse caso, as obras de intelectuais que contribuíram na construção da educação brasileira, tem sido objeto de análise dos pesquisadores que têm dificuldades em localizar ou mesmo estudar o conjunto da produção de um autor devido ao volume, quantidade ou mesmo complexidade da obra eleita como objeto a ser pesquisado, prejudicando a análise completa do autor. Essa dificuldade exige do pesquisador o estabelecimento de recortes e delimitações. Alerta-se que, se tal recorte não for preciso, corre-se o risco de esfacelar o pensamento de um autor, tomando o que foi afirmado em uma parte pelo conjunto, nesse caso, a categoria da totalidade é fundamental.

Outras questões nebulosas nessas pesquisas se referem às técnicas de investigação. O fundamento inicial de qualquer trabalho científico se constitui da revisão bibliográfica, definida por Fachin (2006, p. 120) como a coleta de informações em materiais de diversos tipos, conduzindo o pesquisador pelas premissas do novo assunto, o qual "[...] se fundamenta em vários procedimentos, desde a leitura até como selecionar, fichar, organizar, arquivar, resumir o texto; ela é a base para as demais pesquisas". 
Fachin (2006) indica os procedimentos metodológicos para tratamento das fontes, que podem ser divididas em primárias e secundárias. As discussões sobre suas características têm produzido referências importantes para a área de História da Educação, visto que sua classificação como fontes primárias ou secundárias varia conforme o objeto a ser estudado. O fundamental é ter clareza de que as fontes são ponto de partida para a pesquisa e assumem características variadas para as quais o pesquisador precisa dar tratamento específico, no qual a problematização caracteriza-se como a espinha dorsal. Refere-se aqui aos acervos pessoais dos autores pesquisados, tais como: livros, traduções, cartas, pinturas, música, poesia, textos literários, entre outras. Estas fontes devem ser interpretadas em sua especificidade na relação ao contexto social de sua produção. Ao estudar a correspondência jesuítica como fonte da história da educação na época do Brasil Colônia, Costa (2008, p. 94) determina que “[...] qualquer fonte primária que é utilizada em pesquisa de História da Educação, em particular, é fruto da época em que foi produzida e, portanto, está eivada da cultura da época com que era considerado vício ou virtude".

Os dados e informações utilizados como fontes primárias podem ser obras de interesse científico do pesquisador ou encomendas específicas de uma organização, registros oficiais e outros documentos, todos permeados por questões políticas e ideológicas próprias do espaço e época em que foram produzidos, sendo mero reducionismo crer que o seu conteúdo representa a realidade completa. Desta forma, o pesquisador se encontra frente à exigência de considerar para além da aparência e compreender o contexto econômico, social, político e cultural. A compreensão do contexto social é fundamental para a compreensão da obra do autor eleito como fonte de pesquisa, aplicando o mesmo rigor exigido nas pesquisas históricas de modo geral. A delimitação, quando dada pela data de publicação da obra, pode parecer fácil, contudo isto não dispensa um olhar geral para os acontecimentos históricos, faz-se necessário conciliar a história local, regional, nacional e internacional, com base na categoria da mediação. (NETTO, 2006).

Em se tratando de fontes, Lombardi (2004, p. 158) considera importante que nada seja excluída do processo inicial de investigação, visto que "[...] a diversificação pode revelar aspectos e características diferenciadas das relações do homem, quer sejam com outros homens ou com o meio em que vive". Esta diversificação de fontes representa os dados secundários, não constam da obra principal, e são, por exemplo, informações escritas em documentos ou fontes orais. Segundo Arnaut de Toledo e Gimenez (2009, p. 111), as fontes secundárias representam uma valiosa fonte de informação, permitindo ainda o embasamento necessário à sua interpretação, indicando situações e períodos, apreciação e "[...] configuração do referencial teórico-metodológico da análise. Entre tantos materiais, podemos relacionar, nessa categoria, os dicionários especializados, as enciclopédias, dados estatísticos, legislações e outras fontes de referência".

Outro material que pode ser avaliado é a literatura de apoio, necessária para o estabelecimento do diálogo com as pesquisas mais recentes na área acadêmica, exemplo encontrado em Galiani (2009, p. 22). Ao analisar a obra de John Dewey acerca da educação e democracia, ele define a base teórico-metodológica da sua pesquisa na área de historiografia da educação ao afirmar na introdução de seu texto que "[...] optou-se, como visão norteadora deste livro, pela seleção de algumas obras que permitem uma reflexão sistematizada e abrangente do pensamento do autor e são, por outro lado, as mais referenciadas pelos seus comentadores".

Longe de prescrever um método ou uma fórmula para pesquisas com intelectuais, este percurso por conceitos e definições indica que os métodos utilizados na historiografia da educação com base na obra de intelectuais pouco se diferencia dos métodos utilizados 
na própria historiografia, estabelecendo sua construção teórica por meio da análise de fontes primárias e secundárias, obedecendo aos critérios da metodologia científica, cercada de análises que possibilitem o entendimento das informações no contexto de sua produção e, finalmente, fornecendo novos conhecimentos sobre a educação. Entretanto, não é possível desprezar referências especializadas citadas no decorrer deste artigo.

\section{CONSIDERAÇÕES FINAIS}

A área de historiografia da educação se apresenta como espaço de debate e amplas discussões sobre o processo de elaboração da escrita da história, sem se distanciar dos métodos científicos e da análise do contexto social de produção das fontes, incluindo os interesses pessoais, ideológicos e políticos envolvidos no processo. Assim, a produção histórica acerca da educação está ligada à da história geral, objetivando interpretar os dados e informações dentro das condições sociais e políticas de cada época, sem descartar a influência da formação do próprio pesquisador.

$\mathrm{Na}$ identificação dos procedimentos utilizados na elaboração de estudos em história da educação a respeito da obra de intelectuais, um dos pontos essenciais é a diferenciação espaço-tempo, uma vez que, na contemporaneidade, o intelectual tradicional é substituído pelo orgânico, ligado aos interesses do seu grupo de origem ou sua inserção de classe social, tendendo a se posicionar diante de situações que exijam sua atuação no bojo de suas concepções ideológicas do grupo a que se filia.

As pesquisas em obras de intelectuais representam uma das fontes para a história da educação, e devem se revestir do necessário rigor metodológico e de base teórica adequada, identificando as condições sociais e políticas presentes no contexto de sua elaboração, bem como a ideologia, os interesses e a formação acadêmica e religiosa do autor estudado. Segundo Kelley (1990), a história intelectual tem seus próprios objetivos, valores e questões que pesam sobre a condição humana, e estes não podem vir a ser valorizados e perseguidos no nível da teoria, os quais, alienados da interlocução com disciplinas vizinhas, tendem a negligenciar os problemas práticos do oficio histórico próprio ${ }^{4}$.

Não é possível o estudo de um "intelectual" que se volta para questões educacionais ou sociais isolando-o da vida material que dá sentido e significado para o papel que desempenha em determinado momento histórico. Isto é, não se pode desconsiderar aquilo que o autor diz dele mesmo ou o que se tem repetido pela historiografia educacional. Portanto, para alcançar resultados profícuos, faz-se necessário uma análise do conjunto da obra desse autor na intrincada rede de relações e fatos políticos, econômicos, culturais e sociais na qual ele forjou sua perspectiva teórica e política.

\section{REFERÊNCIAS}

ARNAULT DE TOLEDO, C. A.; GIMENEZ, J. C. Educação e pesquisa: fontes e documentos. In: CASIMIRO, A. P. B. S.; LOMBARDI, J. C.; MAGALHÃES, L. D. R. A pesquisa e a preservação de arquivos e fontes para a educação, cultura e memória. Campinas, SP: Alínea, 2009, p. 109-125. 
BEIRED, J. L. B. A função social dos intelectuais. In: AGGIO, A. (Org.). Gramsci: a vitalidade de um pensamento. São Paulo: Fundação Editora da UNESP, 1998.

CADIOU, F. S. et al. Como se faz a história: historiografia, método e pesquisa. Petrópolis, RJ: Vozes, 2007.

CASTANHO, S. Teoria da história e história da educação: por uma história cultural não culturalista. Campinas, SP: Autores Associados, 2010.

CARDOSO, Ciro Flamarion. História e Paradigmas Rivais. In: ARDOSO, Ciro F.; VAINFAS, Ronaldo. (Orgs.). Domínios da História: Ensaios de Teoria e Metodologia. Rio de Janeiro: Campus, 1997, pp. 1-23.

CERQUEIRA, M. N. O intelectual e a liberação do pensamento (Gramsci e Said). ENCONTRO DE HISTÓRIA ANPUH - Rio. Identidades, 13. Anais... Rio de Janeiro, 2008. Disponível em: <http://www.encontro2008.rj .anpuh. org/ resources/content/anais />. Acesso em: 12 jul. 2011.

COSTA, C. J. O epistolário jesuítico como fonte privilegiada de pesquisa sobre história da educação no Brasil Colonial. In: MACHADO, M. C. G. M.; OLIVEIRA, T. (Orgs.). Educação na história. São Luis: Editora UEMA, 2008, p. 73-95.

ELIAS, N. A sociedade de corte: Investigação sobre a sociologia da realeza e da aristocracia de corte. Rio de Janeiro: Jorge Zahar, 2001.

Mozart - Sociologia de um gênio. Rio de Janeiro: Jorge Zahar, 1995.

FACHIN, O. Fundamentos de metodologia. São Paulo: Saraiva, 2006.

FALCON, F. História das ideias. In: CARDOSO, Ciro Flamarion; VAINFAS, Ronaldo (Orgs.). Domínios da história: ensaios de teoria e metodologia. Rio de Janeiro: Campus, 1997. p. 139-188.

FERRÉOL, G.; NORECK, J. P. Introdução à sociologia. São Paulo: Ática, 2007.

GALIANI, C. Educação e democracia em John Dewey. Maringá, PR: EDUEM, 2009.

GRAMSCI, A. Os intelectuais e a organização da cultura. Rio de Janeiro: Civilização Brasileira, 1968.

HOBSBAWM, E. Sobre a história. São Paulo: Companhia das Letras, 1998.

KELLEY, D. R. Horizons of intellectual history: Retrospect, circumspect, prospect. Journal of the History of Ideas, v. 48, n. 1, p. 143-169, Jan.-Mar. 1987.

What is happening to the history of ideas? Journal of the History of Ideas, v. 51, n. 1, p. 3-25, Jan.-Mar. 1990.

LAKATOS, E. M.; MARCONI, M. A. Sociologia geral. São Paulo: Atlas, 2006. 
LE GOFF, J. História e memória. Campinas, SP: Editora da UNICAMP, 1990.

LEONEL, Z. Tendência atual da história da educação. In: SCHELBAUER, A. R.; LOMBARDI, J. C.; MACHADO, M. C. G. (Orgs.). Educação em debate: perspectivas, abordagens e historiografia. Campinas, SP: Autores Associados, 2006. p. 53-71.

LOMBARDI, J. C. História e historiografia da educação. In. ; NASCIMENTO, M. I. M. Fontes, história e historiografia da educação. Campinas, SP: Autores Associados, 2004. p. 141-177.

História e historiografia da educação: fundamentos teórico-metodológicos. In: SCHELBAUER, A. R.; LOMBARDI, J. C.; MACHADO, M. C. G. (Orgs.). Educação em debate: perspectivas, abordagens e historiografia. Campinas, SP: Autores Associados, 2006. p. 73-98.

LOPES, E. M. T.; GALVÃO, A. M de O. História da Educação. Rio de Janeiro: DPEA, 2001 .

LÖWY, M. Para uma sociologia da intelligentsia capitalista. In: (Org.) LÖWY, M. Para uma sociologia dos intelectuais revolucionários. São Paulo: Livraria Editora Ciências Humanas, 1979. p. 1-92.

MACHADO, M. C. G.. Rui Barbosa: pensamento e ação. Campinas, SP: Autores Associados, 2002.

MALINA, A.; OLIVEIRA, V. M.; AZEVEDO, A. C. B. Uma discussão sobre o conceito de intelectual em Karl Mannheim e Antonio Gramsci. Trabalho \& Educação, v. 16, n. 2, p. 69-80, jul. / dez. 2007.

MARRACH, S. Outras histórias da educação: do iluminismo à indústria cultural (1823 2005). São Paulo: Editora UNESP, 2009.

MAXIMO, A. C. Os intelectuais e a educação das massas: o retrato de uma tormenta. Campinas, SP: Autores Associados, 2000.

NETTO, J. P. Relendo a teoria marxista da história. In: SAVIANI, D.; LOMBARDI, J. C.; SANFELICE, J. L. (Orgs.). História e História da Educação: o debate teóricometodológico atual. $3^{\mathrm{a}}$ ed. Campinas, SP: Autores Associados: HISTEDBR, 2006 (Coleção Educação Contemporânea), p. 50-64.

NÓVOA, A. História da Educação: Percursos de uma disciplina. Lisboa, 1999.

SARTRE, J.P. Em defesa dos intelectuais. São Paulo: Ática, 1965.

SAVIANI, D. O debate teórico e metodológico no campo da história e sua importância para pesquisa educacional. In: ; LOMBARDI, J. C.; SANFELICE, J. L. (Orgs.). História e história da educação. 3. ed. Campinas, SP: Autores Associados/HISTEDBR, 2006. p. 7-16. 
VIEIRA, C. E. Intelligentsia e intelectuais: sentidos, conceitos e possibilidades para a história intelectual. Revista Brasileira de História da Educação, Campinas, SP: Autores Associados, n. 16, p. 63-85, jan./abr. 2008.

História dos intelectuais: representações, conceitos e teorias. Disponível em: <http://www.sbhe.org.br/novo/congressos/cbhe4/coordenadas/eixo06>. Acesso em: 15 fev. 2012.

VON HUMBOLDT, W. Sobre a tarefa do historiador. In: MARTINS, E. R. (Org.). História pensada. São Paulo: Contexto, 2010. p. 82-100.

VON RANKE, L. O conceito de história universal. In: MARTINS, E. R. (Org.). História pensada. São Paulo: Contexto, 2010. p. 201-215.

\section{Notas}

\footnotetext{
${ }^{1}$ Pedagoga, mestre em educação pela Universidade Estadual de Maringá, doutora em Filosofia e História da Educação pela Universidade Estadual de Campinas, Professora do curso de pedagogia, do mestrado e doutorado em educação da Universidade Estadual de Maringá e coordenadora do GT - Maringá do Grupo de Estudos e Pesquisas «História, Sociedade e Educação no Brasil»(HISTEDBR). mcgmachado@ uem.br

${ }^{22}$ Cientista Social, mestre em Ciências Sociais pela Universidade Estadual de Londrina, doutorando em Educação da Universidade Estadual de Maringá, Professor da Universidade Estadual do Paraná e membro do GT - Maringá do Grupo de Estudos e Pesquisas História, Sociedade e Educação no Brasil (HISTEDBR). dorigao@fecea.br
}

\footnotetext{
${ }^{3}$ Pedagoga, especialista em Arte e Educação pelo Instituto Paranaense de Ensino, mestre em Educação pela Universidade Estadual de Maringá, doutoranda do Programa de Pós-Graduação em Educação (PPE/UEM Mestrado/Doutorado), professora orientadora de trabalho de Conclusão de Curso em nível de Pós-Graduação a Distância pela UniCesumar.

${ }^{4}$ Intellectual history has its own aims, values, and questions to pose about the human condition; and these cannot ultimately be honored and pursued on the level of theory, which, distracted by the conversations of neighboring disciplines, tends to neglect the practical problems of its own historical craft.
}

Recebido: fevereiro-16 $\quad$ Aprovado: março-16 